\title{
Standardization of Fermentation Parameters for Beer Production from Sweet Sorghum (Sorghum bicolour (L.) Moench) Grains
}

\author{
Seema Mesta, G.S. Geeta* and M. Ashwini \\ AICRP on EAAI (Bioconversion Technology), University of Agricultural Sciences, \\ Dharwad-580 005, India \\ *Corresponding author
}

\section{A B S T R A C T}

\section{Keywords}

Malting, Mashing, Hops, Fermentation, Alcohol

\section{Article Info}

Accepted:

06 June 2018

Available Online:

10 July 2018
Sweet sorghum is a rich source of starch content and can be diverted for beer production using efficient yeast strains and adopting few fermentation parameters. Five standard yeast strains were screened for their efficiency for beer production. The effect of inoculum level of yeast and fermentation period on $\mathrm{pH}$, tannin content, alcohol content and residual reducing sugars were determined. Different yeast inoculum level $(1 \%, 1.5 \%$ and $2 \%)$ were used for fermentation of wort and it was found that the alcohol content was maximum at 2 per cent inoculum level $(3.33 \%)$ while the $\mathrm{pH}$, tannin content and residual reducing sugars were lowest at this concentration. Among the different fermentation period ( $5 \mathrm{~d}, 7 \mathrm{~d}$ and 10 d), high alcohol content $(4.40 \%)$ was recorded on the tenth day of fermentation. While the $\mathrm{pH}$, tannin content and residual reducing sugars were least at the tenth day. From the experiment, it was found that the yeast strain Saccharomyces cerevisiae NCIM 3580 pitched into wort at a concentration of 2 per cent followed by a ten days fermentation period gave best results in beer production.

\section{Introduction}

One or other type of alcoholic beverage native to its region is prepared and consumed throughout the world. Fermentation has been used for the production of food and beverages for thousands o years. Beer is an alcoholic beverage made from cereals of barley, corn, rice, oat etc. The fundamental basis of the liquor industry is the conversion of sugars to ethyl alcohol and carbon dioxide by the action of enzymes and yeasts. In beverages like palmwine, burukutu, maize beer, sorghum beer etc. are natural involving contact with appropriate inocula and temperature ${ }^{1}$. The process of conversion of cereal starches is not a direct one and involves many steps that are capable of modification. Furthermore, the simultaneous conversion of non-sugar components may have a marked effect on the ultimate product. Different blends of barley malt, roasted barley, oat malt, caramel sugar and other cereal one used to prepare distinctive types of beer or ale. Beer was produced from cassava as a source of carbohydrate wherein "Nwugo" cultivar gave 
the best results among four cultivars used in terms of $\mathrm{pH}$, alcohol and flavour ${ }^{2}$. Beer was produced using 35 per cent sorghum and 25 per cent bajra as adjuncts for brewing ${ }^{3}$. Grist containing 50 per cent unmalted sorghum and 50 per cent malted barley was used for producing beer along with a control brew containing 100 per cent malted barley ${ }^{4}$. In general beer is found to have some medicinal values too. It is found to increase plasma HDL (High Density Lipoprotein) which is a scavenger of cholesterol and so can reduce the risk of cardiovascular disease ${ }^{5}$ and also for treating urolithosis (kidney stone). In tropical countries barley has to be imported from other temperate countries and this involves expenditure of scarce foreign exchange. Hence, sweet sorghum is a new potential substitute for barley which can be used as an alternate substrate and also raise economic benefits.

\section{Materials and Methods}

Standard yeast cultures of Saccharomyces cerevisiae NCIM 3455, NCIM 3551, NCIM 3570, NCIM 3580 and NCIM 3391 were obtained from NCIM, Pune and maintained on yeast extract peptone dextrose agar (YEPDA). Overnight grown fresh yeast cultures grown in YEPD broth were used as inoculum. The grains of sweet sorghum variety "SSV-84" were selected as a source of brewing material. The grains were malted for 3 days after a soaking period of 16 hours in cold tap water. The malt was then kilned at $50^{\circ} \mathrm{C}$ in a hot air oven for 24 hours. The kilned grains were broken into grits by running through a mixer at low speed. Double mashing programme was then carried out with a grist to water ratio of $1: 3$ for temperature rests of $45^{\circ} \mathrm{C}$ and $60^{\circ} \mathrm{C}$ along with commercial $\alpha$-amylase for maximum saccharification. The concentration of 1 per cent of amylase enzymes (Palkozyme, courtesy: M/s Maps India Ltd., Ahmedabad) at $50^{\circ} \mathrm{C}$ for $24 \mathrm{~h}$ of incubation was used. After mashing, the mash was double filtered through muslin cloth and the hydrolysate (wort) obtained was boiled for an hour. After 30 minutes of boiling hops (acid extracted, courtesy: M/s U. B. Breweris, Mangalore) was added @ 40 ppm sugar was added as an adjunct to make up the brix to $20^{\circ} \mathrm{C}$ with the help of ERMA refractometer. The wort was cooled, filtered and $\mathrm{pH}$ was adjusted to 5.0. The wort was the pitched with overnight grown cultures of five yeast strains and kept for aerobic fermentation for $24 \mathrm{~h}$ followed by creating aerobic conditions. The yeast inoculum level used for standardization were 1 per cent, 1.5 per cent and 2 per cent and the fermentation period were 5 days, 7 days and 10 days. The $\mathrm{pH}$, tannin content, alcohol content and residual reducing sugars of the beer samples obtained after fermentation were estimated. Pilot scale beer production was done using the most suitable yeast strain, inoculum level and fermentation period.

The $\mathrm{pH}$ of the wort and the beer samples were recorded by using the $\mathrm{pH}$ meter of Analog model (Corion Research, USA). The tannin content ${ }^{6}$, alcohol content ${ }^{7}$ and residual reducing sugars ${ }^{8}$ of the beer samples were estimated.

\section{Results and Discussion}

There was significant effect of inoculum size on the $\mathrm{pH}$ of different yeast strains that decreased with increase in the inoculum level (Table 1). The highest $\mathrm{pH}$ (4.67) was recorded in the beer treated with 1 per cent inoculum level, while the lowest $\mathrm{pH}$ was recorded at 2 per cent inoculum level (4.29). Among the yeast strains, high $\mathrm{pH}$ (4.56) was observed in yeast strain Saccharomyces cerevisiae NCIM 3580 and Saccharomyces cerevisiae NCIM 3391. The decrease in $\mathrm{pH}$ could be due to the production of organic acids formed during the early stages of fermentation. A $\mathrm{pH}$ range of 4.1 to 5.15 and 4.1 to 5.1 was observed in the 
beer prepared from barley using sorghum and bajra as malt adjuncts respectively in different combinations ${ }^{9}$.

From the results (Table 1), it is clear that the tannin content decreased significantly with increase in inoculum level. The highest tannin content was observed at an inoculum level of 1 per cent $(5.60 \mathrm{mg} / 100 \mathrm{~mL})$ while the lowest tannin content was recorded at 2 per cent $(4.65$ $\mathrm{mg} / 100 \mathrm{~mL}$ ) of the inoculum level. Among the yeast strains, Saccharomyces cerevisiae NCIM 3580 recorded the lowest tannin content $(4.50 \mathrm{mg} / 10 \mathrm{~mL})$. The variation in tannin content with inoculum size could be due to the utilization of considerable amount of tannins by the yeast cells during fermentation. Tannin content decreased considerably during malting and fermentation 10. However, ethanol content increased significantly with increase in inoculum level (Table 2). High ethanol content was obtained at an inoculum level of 2 per cent $(3.33 \%)$. Among the yeast strains, S.C. NCIM 3580 recorded the highest ethanol content $(3.70 \%)$. In general, the residual reducing sugars decreased significantly with increase in the inoculum level. The highest residual reducing sugars $(8.77 \mathrm{mg} / \mathrm{g})$ was recorded from the beer sample treated with 1 per cent inoculum level while the least was recorded with the treatment of 2 per cent inoculum level (5.87 $\mathrm{mg} / \mathrm{g}$ ). Significant difference was found between the residual reducing sugars of different yeast trains. The yeast strain Saccharomyces cerevisiae NCIM 3551 recorded the highest residual reducing sugars $(7.40 \mathrm{mg} / \mathrm{g}$ ) while the least was recorded by Saccharomyces cerevisiae NCIM 3580 (6.36 $\mathrm{mg} / \mathrm{g}$ ) (Table 2). The results of the effect of fermentation period on the $\mathrm{pH}$, tannin content, ethanol content and residual reducing sugars are presented in Table 3 and 4. Highest $\mathrm{pH}$ (4.41) was obtained at the fifth day of fermentation that decreased upto tenth day. The lowest $\mathrm{pH}$ (4.17) was obtained at the tenth day. Among the yeast strains Saccharomyces cerevisiae NCIM 3580 showed the highest $\mathrm{pH}$ (4.38). The difference within the yeast strains was found non-significant. The decrease in $\mathrm{pH}$ along with fermentation was due to the efflux of $\mathrm{H}^{+}$ions as a byproduct of the transport system ${ }^{11}$. A pH of 5.5 in sorghum wort was recorded initially which decreased gradually during fermentation and a final $\mathrm{pH}$ of 4.0 was recorded at the fifth day of fermentation ${ }^{12}$. Significant difference in tannin content at different days of fermentation was noted. Highest tannin content was observed in beer fermented for 5 days $(4.92 \mathrm{mg} / 10 \mathrm{~mL})$ while, the lowest tanning content was recorded at the tenth day of fermentation (4.69 mg/10 mL). The yeast strain Saccharomyces cerevisiae NCIM 3551 recorded highest tannin content $(5.20 \mathrm{mg} / 100 \mathrm{~mL})$ while least tannin content was observed by fermentation with Saccharomyces cerevisiae NCIM 3580 (4.47 $\mathrm{mg} / 100 \mathrm{~mL}$ ). The variation in tannin content may be due to the variation in the utilization of tannins.

There was a progressive increase in the alcohol content of beer with increase in the period of fermentation (Table 3). The highest alcohol content was observed in beer fermented for 10 days $(4.40 \%)$ which was found to be non-significant with alcohol content obtained at 7 days fermentation $(4.39 \%)$. The yeast strain Saccharomyces cerevisiae NCIM 3580 showed the highest alcohol content (4.57\%). This can be attributed to the fact that longer fermentation can further deplete glucose, maltose and fermentable carbohydrates increasing alcohol content upto certain extent. An alcohol content of 2.39 per cent was recorded from Nigerian millet at the end of fifth day of fermentation period ${ }^{13}$. Residual reducing sugars declined significantly from fifth day to seventh day of fermentation but did not show any significant difference on the tenth day. 
Table.1 Effect of different yeast strains and inoculum size on $\mathrm{pH}$ and tannin content of sweet sorghum (SSV-84) beer

\begin{tabular}{|c|c|c|c|c|c|c|c|c|c|c|c|c|}
\hline \multirow{2}{*}{$\begin{array}{l}\text { Inoculum } \\
\text { level }(\%)\end{array}$} & \multicolumn{6}{|c|}{$\mathrm{pH}$} & \multicolumn{6}{|c|}{ Tannin content (mg/100 ml) } \\
\hline & $\begin{array}{c}\text { S.c. } \\
\text { NCIM } \\
3570\end{array}$ & $\begin{array}{c}\text { S.c. } \\
\text { NCIM } \\
3551\end{array}$ & $\begin{array}{c}\text { S.c. } \\
\text { NCIM } \\
3455\end{array}$ & $\begin{array}{c}\text { S.c. } \\
\text { NCIM } \\
3580\end{array}$ & $\begin{array}{c}\text { S.c. } \\
\text { NCIM } \\
3391\end{array}$ & Mean & $\begin{array}{c}\text { S.c. } \\
\text { NCIM } \\
3570\end{array}$ & $\begin{array}{c}\text { S.c. } \\
\text { NCIM } \\
3551\end{array}$ & $\begin{array}{c}\text { S.c. } \\
\text { NCIM } \\
3455\end{array}$ & $\begin{array}{c}\text { S.c. } \\
\text { NCIM } \\
3580\end{array}$ & $\begin{array}{c}\text { S.c. } \\
\text { NCIM } \\
3391\end{array}$ & Mean \\
\hline 1 & 4.61 & 4.63 & 4.64 & 4.78 & 4.70 & 4.67 & 6.02 & 6.30 & 6.17 & 4.68 & 4.85 & 5.60 \\
\hline 1.5 & 4.52 & 4.48 & 4.55 & 4.59 & 4.65 & 4.56 & 5.25 & 5.57 & 5.44 & 4.55 & 4.62 & 5.09 \\
\hline 2 & 4.36 & 4.20 & 4.28 & 4.31 & 4.32 & 4.29 & 4.55 & 5.11 & 4.91 & 4.28 & 4.41 & 4.65 \\
\hline Mean & 4.50 & 4.43 & 4.49 & 4.56 & 4.56 & 4.50 & 5.27 & 5.66 & 5.51 & 4.50 & 4.63 & 5.11 \\
\hline \multicolumn{3}{|l|}{ Source } & \multicolumn{2}{|c|}{$\mathrm{SEm} \pm$} & \multicolumn{2}{|c|}{$\mathrm{CD}$ at $1 \%$} & \multicolumn{3}{|c|}{$\mathrm{SEm} \pm$} & \multicolumn{3}{|c|}{$\mathrm{CD}$ at $1 \%$} \\
\hline \multicolumn{3}{|c|}{ Inoculum level (A) } & \multicolumn{2}{|c|}{0.064} & \multicolumn{2}{|c|}{0.256} & \multicolumn{3}{|c|}{0.030} & \multicolumn{3}{|c|}{0.122} \\
\hline \multicolumn{3}{|l|}{ Strains (B) } & \multicolumn{2}{|c|}{0.083} & \multicolumn{2}{|c|}{ NS } & \multicolumn{3}{|c|}{0.040} & \multicolumn{3}{|c|}{0.158} \\
\hline \multicolumn{3}{|c|}{ Interaction $(\mathrm{A} x \mathrm{~B})$} & \multicolumn{2}{|c|}{0.14} & \multicolumn{2}{|c|}{ NS } & \multicolumn{3}{|c|}{0.069} & \multicolumn{3}{|c|}{0.279} \\
\hline
\end{tabular}

S.c. - Saccharomyces cerevisiae.

Initial $\mathrm{pH} \quad: 5.2$

NS - Non significant

Initial tannin content $: 13.15 \mathrm{mg} / 100 \mathrm{ml}$ 
Table.2 Effect of different yeast strains and inoculum size on alcohol content and residual reducing sugars of sweet sorghum (SSV-84) beer

\begin{tabular}{|c|c|c|c|c|c|c|c|c|c|c|c|c|}
\hline \multirow{2}{*}{$\begin{array}{l}\text { Inoculum } \\
\text { level }(\%)\end{array}$} & \multicolumn{6}{|c|}{ Alcohol content $(\%)$} & \multicolumn{6}{|c|}{ Residual reducing sugars (mg/g) } \\
\hline & $\begin{array}{c}\text { S.c. } \\
\text { NCIM } \\
3570\end{array}$ & $\begin{array}{c}\text { S.c. } \\
\text { NCIM } \\
3551\end{array}$ & $\begin{array}{c}\text { S.c. } \\
\text { NCIM } \\
3455\end{array}$ & $\begin{array}{c}\text { S.c. } \\
\text { NCIM } \\
3580\end{array}$ & $\begin{array}{c}\text { S.c. } \\
\text { NCIM } \\
3391\end{array}$ & Mean & $\begin{array}{c}\text { S.c. } \\
\text { NCIM } \\
3570\end{array}$ & $\begin{array}{c}\text { S.c. } \\
\text { NCIM } \\
3551\end{array}$ & $\begin{array}{c}\text { S.c. } \\
\text { NCIM } \\
3455\end{array}$ & $\begin{array}{c}\text { S.c. } \\
\text { NCIM } \\
3580\end{array}$ & $\begin{array}{c}\text { S.c. } \\
\text { NCIM } \\
3391\end{array}$ & Mean \\
\hline 1 & 2.98 & 2.26 & 2.34 & 3.52 & 3.11 & 2.84 & 8.73 & 9.32 & 9.14 & 8.28 & 8.42 & 8.77 \\
\hline 1.5 & 3.18 & 2.29 & 2.39 & 3.69 & 3.64 & 3.03 & 5.83 & 6.47 & 6.22 & 5.41 & 5.57 & 5.90 \\
\hline 2 & 3.34 & 2.48 & 3.26 & 3.89 & 3.69 & 3.33 & 5.81 & 6.43 & 6.19 & 5.39 & 5.55 & 5.87 \\
\hline Mean & 3.16 & 2.39 & 2.66 & 3.70 & 3.48 & 3.07 & 6.79 & 7.40 & 7.18 & 6.36 & 6.51 & 6.85 \\
\hline \multicolumn{3}{|l|}{ Source } & \multicolumn{2}{|c|}{ SEm \pm} & \multicolumn{2}{|c|}{$\mathrm{CD}$ at $1 \%$} & \multicolumn{3}{|c|}{ SEm \pm} & \multicolumn{3}{|c|}{$\mathrm{CD}$ at $1 \%$} \\
\hline \multicolumn{3}{|c|}{ Inoculum level (A) } & \multicolumn{2}{|c|}{0.013} & \multicolumn{2}{|c|}{0.054} & \multicolumn{3}{|c|}{0.078} & \multicolumn{3}{|c|}{0.310} \\
\hline \multicolumn{3}{|l|}{ Strains (B) } & \multicolumn{2}{|c|}{0.017} & \multicolumn{2}{|c|}{0.071} & \multicolumn{3}{|c|}{0.101} & \multicolumn{3}{|c|}{0.401} \\
\hline \multicolumn{3}{|c|}{ Interaction $(\mathrm{A} \times \mathrm{B})$} & \multicolumn{2}{|c|}{0.030} & \multicolumn{2}{|c|}{0.122} & \multicolumn{3}{|c|}{0.175} & \multicolumn{3}{|c|}{ NS } \\
\hline
\end{tabular}

NS - Non significant

S.c. - Saccharomyces cerevisiae.

Initial reducing sugars $\quad: 73.72 \mathrm{mg} / \mathrm{g}$ 
Table.3 Effect of yeast strains and fermentation days on $\mathrm{pH}$ and tannin content of sweet sorghum (SSV-84) beer

\begin{tabular}{|c|c|c|c|c|c|c|c|c|c|c|c|c|}
\hline \multirow{2}{*}{$\begin{array}{l}\text { Fermentation } \\
\text { period } \\
\text { (days) }\end{array}$} & \multicolumn{6}{|c|}{$\mathrm{pH}$} & \multicolumn{6}{|c|}{ Tannin content $(\mathrm{mg} / 100 \mathrm{ml})$} \\
\hline & $\begin{array}{l}\text { S.c. } \\
\text { NCIM } \\
3570\end{array}$ & $\begin{array}{l}\text { S.c. } \\
\text { NCIM } \\
3551\end{array}$ & $\begin{array}{l}\text { S.c. } \\
\text { NCIM } \\
3455\end{array}$ & $\begin{array}{l}\text { S.c. } \\
\text { NCIM } \\
3580\end{array}$ & $\begin{array}{l}\text { S.c. } \\
\text { NCIM } \\
3391\end{array}$ & Mean & $\begin{array}{l}\text { S.c. } \\
\text { NCIM } \\
3570\end{array}$ & $\begin{array}{l}\text { S.c. } \\
\text { NCIM } \\
3551\end{array}$ & $\begin{array}{l}\text { S.c. } \\
\text { NCIM } \\
3455\end{array}$ & $\begin{array}{l}\text { S.c. } \\
\text { NCIM } \\
3580\end{array}$ & $\begin{array}{l}\text { S.c. } \\
\text { NCIM } \\
3391\end{array}$ & Mean \\
\hline 5 & 4.47 & 4.30 & 4.35 & 4.51 & 4.40 & 4.41 & 4.85 & 5.34 & 5.20 & 4.54 & 4.70 & 4.92 \\
\hline 10 & 4.12 & 4.14 & 4.17 & 4.25 & 4.17 & 4.17 & 4.55 & 5.11 & 4.91 & 4.39 & 4.48 & 4.69 \\
\hline Mean & 4.26 & 4.23 & 4.25 & 4.38 & 4.29 & 4.28 & 4.70 & 5.20 & 5.05 & 4.47 & 4.58 & 4.80 \\
\hline \multicolumn{3}{|l|}{ Source } & \multicolumn{2}{|c|}{ SEm \pm} & \multicolumn{2}{|c|}{$\mathrm{CD}$ at $1 \%$} & \multicolumn{3}{|c|}{ SEm \pm} & \multicolumn{3}{|c|}{$\mathrm{CD}$ at $1 \%$} \\
\hline \multicolumn{3}{|c|}{ Interaction (A x B) } & \multicolumn{2}{|c|}{0.128} & \multicolumn{2}{|c|}{ NS } & \multicolumn{3}{|c|}{0.051} & \multicolumn{3}{|c|}{0.204} \\
\hline \multicolumn{7}{|c|}{$\begin{array}{lc}\text { Initial } \mathrm{pH} & : 5.2 \\
\text { S.c. - Saccharomyces cerevisiae. } \\
\text { Initial tannin content } & : 13.15 \mathrm{mg} / 100 \mathrm{ml} \\
\mathrm{NS} \text { - Non significant. } & \end{array}$} & & & & & & \\
\hline
\end{tabular}


The least residual reducing sugars were obtained on day tenth $(4.12 \mathrm{mg} / \mathrm{g})$ which did not show any significant difference with the residual reducing sugars obtained at the seventh day. Among the yeast strains, Saccharomyces cerevisiae NCIM 3580 recorded the lowest residual reducing sugars $(4.54 \mathrm{mg} / \mathrm{g})$. This difference could be due to the sugar utilizing efficiency of yeast strains and the conversion of reducing sugars to alcohol with time. Residual reducing sugars of $0.166 \mathrm{~g} / 100 \mathrm{~mL}$ was recorded from beer made from a grist containing unmalted sorghum and malted barley 4 .

The above standardized parameters of fermentation reveal that the yeast strain Saccharomyces cerevisiae NCIM 3580 used at 2 per cent inoculum level for a fermentation period of 10 days was suitable for good quality beer production giving a suitable $\mathrm{pH}$ level, low amount of tannins and residual reducing sugars with high alcohol content.

\section{Acknowledgement}

The authors thank the Indian Council of Agricultural Research for providing the laboratory facilities at AICRP on Renewable Energy Sources (Bioconversion Technology).

\section{References}

1. Uzogara SG, Agu LN and Uzogara EO (1990) A review of traditional fermented foods, condiments and beverages in Nigeria: their benefits and possible problems. J. Food Sci. Tech., 6(2): 308312.

2. Rajagopal MV (1977) Production of beer from cassava. J. Food Sci., 42(2): 532533.
3. Dhamija SS and Singh DP (1978) Adjuncts in brewing I. Bajra and Sorghum. J. Food Sci. Tech., 15: 197-201.

4. Goode DL and Arendt EK (2003) Pilot scale production of a lager beer from a grist containing 50\% unmalted sorghum. J. Inst. Brew., 109(3): 208-217.

5. Buemann B, Dyerberg $J$ and Astrup A (2002) Alcohol drinking and cardiac risk. Nutr. Res. Rev., 15: 91-97.

6. Schanderl SH (1970) In: Methods in food analysis. Academic Press, New York, 709.

7. Caputi A, Ueda JM and Brown T (1968) Spectrophotometric determination of chromic complex formed during oxidation of alcohol. Am. J. Enol. Viticult., 19: 160165.

8. Miller GL (1959) Use of dinitrosalicylic acid reagent for determination of reducing sugars. Ann. Chem., 31: 426-428.

9. Dhamija SS and Singh DP (1978) Adjuncts in Brewing I. Bajra and sorghum. J. Food Sci. and Tech., 15: 197201.

10. Uvere PO, Adenyu OD and Mordi C (2000). The effect of germination and kilning on the cyanogemic potential, amylose and alcohol levels of sorghum malts used for Burukutu production. $J$. Sci. Food and Agri., 80: 352-358.

11. Goode DL and Arendt EK (2003) Pilot scale production of a lager beer from a grist containing 50\% unmalted sorghum. J. Inst. Brew., 109(3): 208-217.

12. Okafor N and Aniche GN (1987) Studies on the brewing of lager beer for Nigerian sorghum. J. Food Sci. and Tech., 24: 131134.

13. Agu RC and Obanu ZA (1991) Studies on beer production from Nigerian millet. $J$. Food Sci. and Tech., 28: 81-83.

\section{How to cite this article:}

Seema Mesta, G.S. Geeta and Ashwini, M. 2018. Standardization of Fermentation Parameters for Beer Production from Sweet Sorghum (Sorghum bicolour (L.) Moench) Grains. Int.J.Curr.Microbiol.App.Sci. 7(07): 659-665. doi: https://doi.org/10.20546/ijcmas.2018.707.080 